\title{
Effects of posttraining reinforcement upon retention of a passive avoidance task
}

\author{
NANCY A. MARLIN, CAROLYN GRECO, and RALPH R. MILLER \\ Brooklyn College of the City University of New York, Brooklyn, New York 11210
}

\begin{abstract}
Appetitive stimuli, aversive stimuli, or novel stimuli of relatively low affective value were presented to rats following one-trial passive avoidance training. When tested $24 \mathrm{~h}$ later, the groups did not differ in retention of the passive avoidance task. The results do not support the hypothesis of Huston, Mondadori, and Waser (1974) that posttraining stimuli directly reinforce memory processing. Alternative consequences of posttraining reinforcement are discussed.
\end{abstract}

Huston and Mondadori (1977) have advanced a psychological model of memory in which posttraining reinforcement can directly influence the processing of newly acquired information. In this model they conceptualize posttraining memory processing as an operant response. As such, they argue that memory processing is subject to the law of effect: Presentation of a positive reinforcer rewards processes that strengthen the specific memory, whereas presentation of a negative reinforcer punishes these processes. Thus positive reinforcement following learning should enhance retention, while negative reinforcement should impair retention.

Huston and his colleagues have recently performed a series of experiments that appear to support their model (Huston, Mondadori, \& Waser, 1974; Mondadori, Waser, \& Huston, 1977). In these studies, reinforcement was presented to mice following a single passive avoidance training trial. For example, following training Modadori et al. (1977) gave their food-deprived subjects access to food or placed them in an ice water bath. Subjects were tested $24 \mathrm{~h}$ later for retention of the passive avoidance task. Animals positively reinforced with food 10 or $30 \mathrm{sec}$ after training demonstrated significantly better retention than a control group that had no posttraining reinforcement, and subjects punished with ice water $60 \mathrm{sec}$ after training showed poorer retention than subjects punished 30 or $90 \mathrm{sec}$ after training. Based on these data, Mondadori et al. suggest that the effects of other treatments known to affect retention when administered following learning, such as electroconvulsive shock (ECS) and a variety of

This research was supported by National Science Foundation Grant BMS75-03383 and a grant from the Faculty Award Program of the City University of New York. Ralph R. Miller is supported by National Institute of Mental Health Research Scientist Award MH-00061. We wish to thank Alvin Berk and John Sullivan for their suggestions and comments, and Joan Wessely for her help in preparing the manuscript. Reprint requests should be addressed to Ralph $R$. Miller, Department of Psychology, Brooklyn College of the City University of New York, Brooklyn, New York 11210. pharmacological agents, may be due to their reinforcing properties.

Although the results of Mondadori et al. (1977) are consistent with their hypothesis about the effect of posttraining reinforcement, several questions arise from their analysis. The major theoretical problem concerning these data is the time course inferred for the processing of information following a learning event. If their hypothesis is correct, reinforcement should be maximally effective during or immediately following the information processing generated by a given learning event. Yet, for the identical training task, the results of Mondadori et al. are not consistent in respect to when memorial processing is reinforceable. Food reinforcement is effective 10 or $30 \mathrm{sec}$ following training, while ice water reinforcement is reported not to be effective until $60 \mathrm{sec}$ after training. (It should be noted that for the ice water conditions, the 60 -sec delay group differed from the 30 - and 90 -sec groups, but none of these groups, including the 60 -sec group, differed significantly from the control group that received no further treatment following training.)

Apart from the lack of internal consistency, the temporal gradients obtained in the experiments by Huston and his colleagues are rather different from the gradients observed when memory is disrupted following training in other research. For example, Jacobs and Sorenson (1969) immersed animals in hot water or ice water $0,2,10$, or $30 \mathrm{sec}$ following one-trial passive avoidance training. Relative to control groups, they observed impaired retention only in the 0 - and 2 -sec groups. Similarly, the extensive literature investigating the effects of ECS after a single passive avoidance training trial indicates that the resultant amnesia is most profound when ECS is administered immediately after training, and test performance rapidly asymptotes to control levels within seconds after training (e.g., Chorover \& Schiller, 1965). In view of these data showing that memory becomes relatively invulnerable to disruptive treatments, even treatments as severe as ECS, within seconds following training, it appears unlikely that food or ice water reinforcement presented 
30 or $60 \mathrm{sec}$ after training would be able to directly influence the memory processing itself.

Based on such objections, it appears useful to consider alternative interpretations of studies using the paradigm of Huston et al. (1974). One possibility is that the affective values of the training reinforcer and the posttraining reinforcer may be additive. The aversiveness of the posttraining ice water bath could summate with the aversiveness of the training footshock, thereby producing better passive avoidance than in a control group not placed in ice water following training, or in a group for which the posttraining punishment was sufficiently delayed so as not to be associated with the training task. Similarly, the additive effect of the posttraining reward with the training reinforcer could impair passive avoidance. These predictions are, of course, the converse of the outcome reported by Mondadori et al. (1977).

Another expectation consistent with current theories describing the effects of stimulus interference upon memory (e.g., Runquist, 1975) is that the posttraining reinforcers may interfere with information processing independent of the affective value of the posttraining stimulus. Such "process interference," caused by" a high level of novel posttraining stimulation, rather than the reinforcing properties of the posttraining conditions, would always be injurious to retention. This hypothesis, which is directly supported in the animal literature by the data of Jacobs and Sorenson (1969) described above (c.f. Grosser \& Percy, 1971), could explain impaired retention in animals receiving novel and highly stimulating posttraining treatments, such as an ice water bath, but could not explain improved retention in animals receiving posttraining reward.

The present experiment was designed to investigate the effects of posttraining reinforcement and to compare the predictions of Mondadori et al. (1977) with those described above. This was done by exposing animals to appetitive, aversive, or novel stimulation following one-trial passive avoidance training.

\section{METHOD}

\section{Subjects}

One hundred and fifty-six male Sprague-Dawley-derived rats (Charles River CD) weighing between 380 and $755 \mathrm{~g}$ served as subjects. Subjects were individually housed in continuous light and were maintained on ad-lib Purina Laboratory Chow and 15 min of daily access to water. All animals had been used at least 1 month earlier in a lick-suppression experiment in which they received two or three tone-footshock pairings. Subjects were counterbalanced across the six experimental groups $(n=27)$ for their prior experience.

\section{Apparatus \\ Training and testing were conducted in a step-down apparatus. The grid floor measured $50.8 \times 50.8 \mathrm{~cm}$ and was enclosed on all four sides by walls $57.2 \mathrm{~cm}$ high. A $17.1 \times 9.5 \mathrm{~cm}$ wire mesh platform was centered in the apparatus $11.4 \mathrm{~cm}$ above the grid floor.}

In the same room as the step-down device were the four apparatuses used for the posttraining treatments. These consisted of: a wire mesh holding cage $(24.1 \times 17.8 \times 17.8 \mathrm{~cm})$, an identical holding cage with a water bottle attached, a third holding cage with a solid floor covered by cedar shavings upon which a striped metal divider $(21 \times 18.7 \mathrm{~cm}$, with a $13.3-\mathrm{cm}$ high archway through which the animal could walk) and two pink sponge objects $(5.7 \times 2.5 \mathrm{~cm})$ were placed, and a plastic breeding cage $(45.7 \times 23.5 \times 15.2 \mathrm{~cm})$ filled to a depth of $13 \mathrm{~cm}$ with ice water. The approximate $2-\mathrm{cm}$ gap between the water level and the wire mesh cage covering allowed animals to swim with their heads above water and breathe freely. A $50-\mathrm{dB}$ re. $20 \mu \mathrm{N} / \mathrm{m}^{2}$ white noise was present in the running room at all times.

\section{Procedure}

The experiment was run in two balanced replications. Prior to training, all animals were given repeated 1-min exposures over the 10 days prior to training to the holding cage with the lick tube attached. These exposures continued until greater than $90 \%$ of the animals would begin licking within $15 \mathrm{sec}$ of being placed in the apparatus. This required seven exposures in the first replication and nine exposures in the second. The day before training, all subjects were also given a 1-min exposure to the empty holding cage to minimize any novelty of the apparatus.

On the training day, each subject was placed on the platform and given three step-down exposures (without footshock), each separated by approximately $3 \mathrm{~h}$. On each of these exposures, the subject was left on the floor for $5 \mathrm{sec}$ after stepping down and was then returned to its home cage. These pretraining step-down exposures served to minimize training trial step-down latencies.

Two hours following the third pretraining step-down trial, subjects were each returned to the apparatus for the training trial. Upon stepping down to the floor with all four paws, the subject received a $1-\mathrm{sec}, 1-\mathrm{mA}, 60-\mathrm{Hz}$, scrambled constantcurrent footshock, followed by one of the six posttraining conditions. For the appetitive posttraining reinforcement, subjects were removed from the step-down apparatus $10 \mathrm{sec}$ after the footshock offset, and were placed in the holding cage with the water bottle attached. Subjects failing to initiate licking within $30 \mathrm{sec}$ of placement in the apparatus, or failing to lick for at least 20 of the next $30 \mathrm{sec}$ once having begun to lick were discarded and replaced by new animals from the same subject pool. Animals in the two posttraining aversive reinforcement groups were removed from the training apparatus immediately after the footshock and were either placed in the ice water bath for $10 \mathrm{sec}$, or placed in the holding cage for $60 \mathrm{sec}$ after training and then exposed to the ice water bath for 10 sec. Similarly, the two high-stimulation groups were given $30 \mathrm{sec}$ of high stimulation either immediately following training or following $60 \mathrm{sec}$ spent in the holding cage after training. For the high-stimulation condition, subjects were placed in the holding cage containing the cedar chips and the striped divider. While they were in the apparatus, a recording of electrically synthesized music was played (80-dB maximum), the room lights were flashed on and off once every $2 \mathrm{sec}$ (on for approximately $1 \mathrm{sec} /$ cycle), and the experimenter gently swung the apparatus in a horizontal figure-eight pattern that was completed approximately once every $5 \mathrm{sec}$. The sixth group consisted of control animals that were placed in the holding cage for $60 \mathrm{sec}$ immediately after training. All subjects were returned to their home cages following their posttraining treatment.

Twenty-four hours later all subjects were tested for retention of the passive avoidance task. Each animal was placed on the platform of the step-down apparatus as in training, and its latency to step down with all four paws was recorded using a 600 -sec ceiling. 

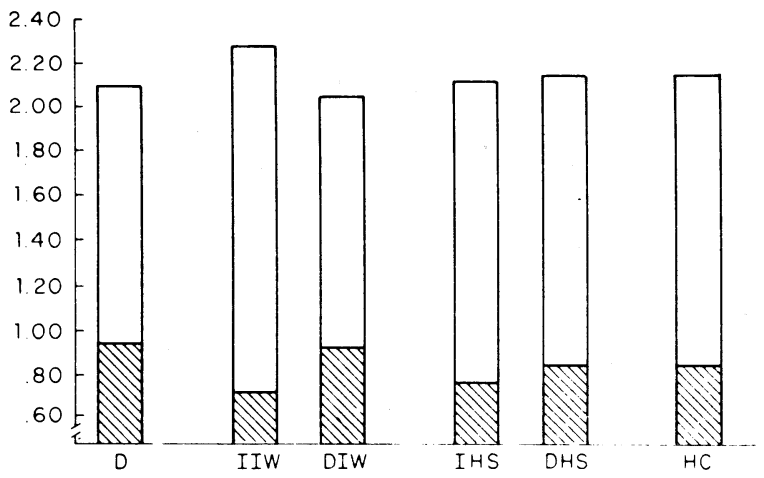

Figure 1. Training (striped bars) and test (solid bars) stepdown scores for each of the posttraining treatments. Posttraining treatments are: drinking (D), immediate ice water (IIW), delayed ice water (DIW), immediate high stimulation (IHS), delayed high stimulation (DHS), or holding cage (HC). Ceiling score $=2.78 \log$ sec.

\section{RESULTS}

The data were transformed to log latencies to normalize the distributions and were pooled across replications as no replication effects were observed (all ps > .05). As shown in Figure 1, there were no significant differences in training step-down scores $[F(5,156)=.44, p>.80]$ or in test scores $[F(5,156)=.28, p>.90]$ for the six groups. Post hoc comparisons using Tukey's test for repeated measures revealed that the test latencies for all of the groups were significantly greater than the training latencies (all ps $<.01$ ), demonstrating retention of the passive avoidance task in each of the groups.

All subjects were observed continuously throughout their posttraining exposure. Upon being placed in the ice water bath, subjects in this posttraining condition swam vigorously with their heads above water. Consistent with our intention that the high-stimulation condition provide novel stimulation of relatively low affective value, subjects in this posttraining condition did not appear fearful. They were observed to explore the apparatus, and little defecation occurred.

\section{DISCUSSION}

According to the memory model of Huston and Mondadori (1977), the effects of the different posttraining reinforcers should have produced differences in retention. Although the present experiment was designed to include the time intervals that Mondadori et al. (1977) found to be most effective in producing such results, no differences in retention were found. This finding suggests that the direct effects of posttrial reinforcement upon memory observed by Mondadori et al. may be of very limited generality. In evaluating this conclusion, careful note must be taken of the procedural differences between the present study and the study of Mondadori et al. (1977). Included among these differences are the use of rats as opposed to mice as subjects, and of water rather than food as the appetitive posttraining reinforcer. Such changes may account for the failure to obtain the effects reported by Mondadori et al., although this again suggests the limited circumstances to which the memory model of Huston and Mondadori (1977) may be applicable.

A problem in interpreting the results of the present experiment is the existence of ceiling effects. Thirty-six percent of the subjects, ranging from $26 \%$ of the delayed high-stimulation group to $48 \%$ of the immediate ice water group, did not step down from the platform during the 600 -sec test trial. Although somewhat decreasing the sensitivity of the experiment to effects of the posttraining conditions, ceiling scores were absent in a sufficient number of animals to provide a valid test of the hypothesis given the present experimental parameters. This is particularly true of the group receiving the posttraining punishment, as the high-acquisition baseline permitted much room for attenuation of memory. Mondadori et al. (1977) employed a 150-sec ceiling in testing, but do not report the number of animals assigned a ceiling test score.

The present experiment does not indicate a clear alternative to the posttraining reinforcement model, as it also failed to provide support for either the hypothesis concerning the additive effects of reinforcers or the possibility that posttraining stimulation can produce process interference (Runquist, 1975). These failures may have been due to the time interval present between the offset of the training footshock and the placement of the subject in any of the posttraining conditions. Even for the immediate ice water and immediate high-stimulation groups, an interval of between 3 and $5 \mathrm{sec}$ was required to physically remove an animal from the step-down apparatus and place it in the appropriate posttraining apparatus. As previously stated, memory processes appear to become relatively invulnerable to disruption within a few seconds after training; therefore, this delay preceding posttraining treatment may have allowed sufficient processing of the information concerning the learning event to mask any of the hypothesized effects. To investigate this possibility, further research is currently in progress using a training apparatus in which posttraining conditions follow training more immediately than in the present experiment.

\section{REFERENCES}

Chorover, S. L., \& Schiller, P. H. Short-term retrograde amnesia in rats. Journal of Comparative and Physiological Psychology, 1965, 59, 73-78.

Grosser, G. S., \& Percy, H. E. Post shock immersion of mice without memory disruption. Journal of Comparative and Physiological Psychology, 1971, 76, 119-122.

Huston, J. P., \& Mondadori, C. Reinforcement and memory: A model. Activitas Nervosae Superioris, 1977, 19, 17-19.

Huston, J. P., Mondadori, C., \& WASER, P. G. Facilitation of learning by reward of posttrial memory processes. Experientia, 1974, 30, 1038-1040.

Jacobs, B. L., \& Sorenson, C. A. Memory disruption in mice by brief posttrial immersion in hot or cold water. Journal of Comparative and Physiological Psychology, 1969, 68, 239-244.

Mondadori, C., Waser, P. G., \& Huston, J. P. Timedependent effects of post-trial reinforcement, punishment, or ECS on passive avoidance learning. Physiology and Behavior, 1977, 18, 1103-1109.

RuNQuist, W. N. Interference among memory traces. Memory \& Cognition, 1975, 3, 143-159.

(Received for publication January 20, 1978.) 